\title{
The Integration and Development of Online New Media Marketing and Traditional Marketing
}

\author{
Zhian Zhu' 1, 2, a, Gongqian Liang ${ }^{1}$ \\ ${ }^{1}$ School of Management, Northwestern Polytechnic University, Xi'an 710072, China; \\ ${ }^{2}$ School of Economics and Management, Xian University of Technology, Xi'an 710032, China. \\ azza212@163.com
}

Keywords: Internet new media, marketing, traditional marketing, integration.

\begin{abstract}
With the rapid development of new technologies, the spread of online new media, production methods and the spread of the communication environment have also brought about greater changes in the dissemination of subjects compared to the past. The development of new media has led to the formation of new media marketing methods, giving tradition At the same time as the marketing model affects, it also provides new ideas and new methods for the development of the company. However, new media marketing is also faced with many obstacles due to the lack of awareness of new media marketing, the lack of existing domestic new media marketing talents, and the inadequacy of the audience's needs. In addition, traditional marketing methods need to adapt to the development of the market economy and constantly break through the existing development dilemma. Therefore, in the current market environment, the advantages of the new media and the old media can be integrated to give full play to the role of the new media channels and the authority of the traditional media industry. This will enable the new media and traditional marketing to develop harmoniously and harmoniously.
\end{abstract}

\section{Introduction}

With the rapid development and widespread use of network-led new media, a new digital era has arrived. In order to adapt to the wave of digitization, for some time now many newspapers have actively participated in the integration and cooperation of new technologies and new media. They have made early explorations and achieved remarkable results. Newspaper network interaction is also a phenomenon that appears in this context. The combination of traditional media and new media has become an irresistible trend that covers the entire media development [1].

\section{The Concept of Traditional Media and New Media}

Traditional media and new media Traditional media and new media are a pair of relative concepts. They mainly refer to the fact that during the evolution and development of the media, some media were produced early, and they regularly published information or provided information to the general public through some mechanical device [2]. The media for education and entertainment exchange activities are called traditional media, such as newspapers, radio, and television; and new media refer to media that have emerged and developed along with the birth of new technologies. Since 2004, various new technologies have been introduced. Promoted by the new media represented by the Internet has become an indispensable form of media in modern society [3].

\section{The Integration of Traditional Media and New Media}

\subsection{The Main Body of Media Integration.}

In the traditional theory of communication, the main body of communication refers to the initiator of the communication behavior, that is, the media agency engaged in the collection, selection, processing, and dissemination of information. For example, the main body of newspapers is newspapers. Specifically, they are the staff of the newspapers or the employees. They collect 
information through daily news information, and after a certain processing and finishing, they send it to the newspaper readers through newspapers. In the network communication, based on the technical characteristics of the network media, participants of each network activity can actually be communicators and become the main body of communication activities. They spread out the information they have obtained, but at the same time they can become the target audience of other participants in the network activity through continuous information acquisition. Then through the continuous dissemination of information and the reception of you, the main body of dissemination in the network communication is also in uncertain pluralism. In the cooperation between traditional newspaper media and online new media, interaction between online newspapers effectively integrates traditional communication subjects such as newspapers and disseminate of new media. The newspaper opened an online version [4]. On the surface, this is still one party providing information to the other party to receive information. However, it should be noted that the opening of the online newspaper has actually weakened the main body of the communicators and the passive situation of the recipients. For example, online newspaper commentary and other columns are set up, in which online communication participants often discuss the news information, and these commentary contents often become the basis and source of online newspaper reporters and editors of new news information. In addition, some participants including these journalist editors can also obtain new information knowledge from these thread discussions. In this case, the interaction of online newspapers actually has the characteristics of the main body of traditional media communicators. In this way, the disadvantages of the modernization of the main body of communication and the lack of interaction and communication in the traditional newspaper media's dissemination structure have been improved, and the mutual understanding between the two sides has been actively strengthened, the communication activities can be better carried out, and the newspaper has acquired a new Expansion capacity [5].

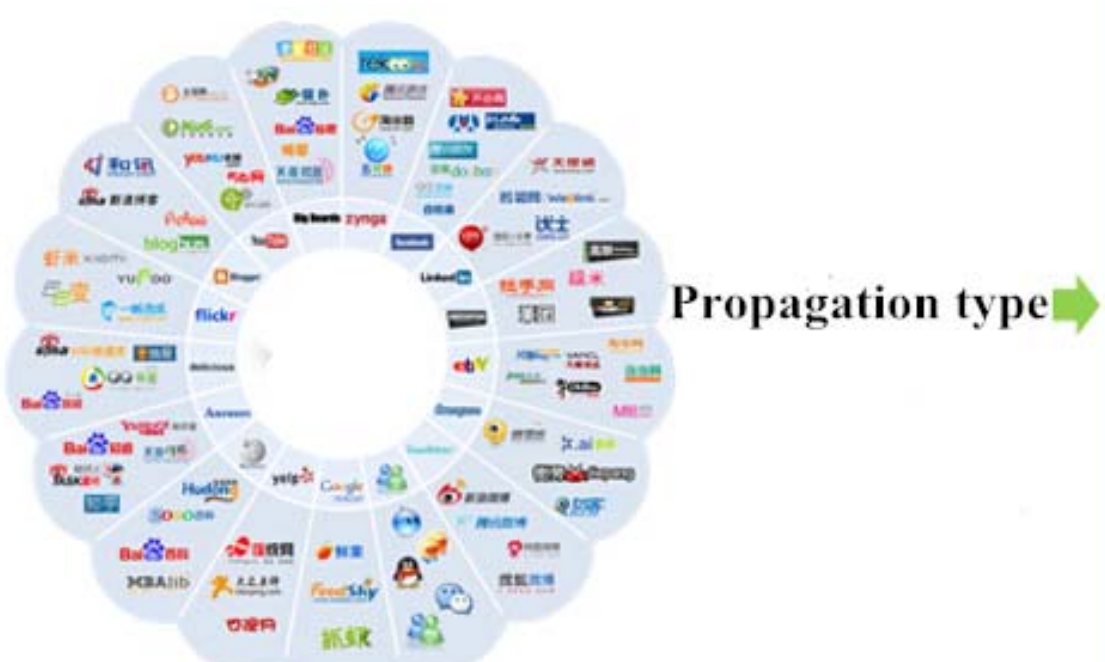

New network media

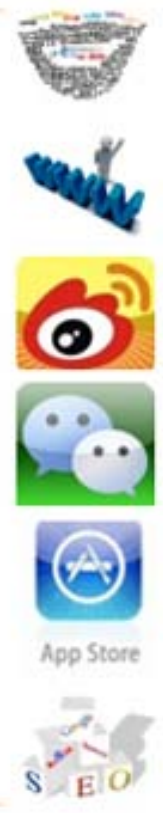

Fig 1. Online new media marketing

\subsection{Communication Content That the Media Infiltrates.}

The newspaper has been in existence for hundreds of years. In terms of its dissemination, it has also undergone a general experience of simple merchandise and commercial information, academic articles such as political philosophy, and publication-based development. Today's newspapers, no matter what type of newspapers they belong to, are mostly published in news, information, reviews, commercial advertisements, and supplements. Newspapers are subject to restrictions on the length of their pages. Only newspaper editors and other newspapers can disseminate information to the main body according to a certain standard to select and reject a large number of information. In addition, due to the limitation of newspaper publishing time, the information update is often lagging behind. 
Compared to newspapers, the network is characterized by massiveness in the dissemination of information, and it can be free from space limitations through technical means such as hyperlinks. The network information also shows the characteristics of immediacy, updating much faster than newspapers. Therefore, the new media on the Internet must be much larger than the newspapers in terms of content or content, as well as the speed of information update. For the modern people in the information society where information is changing frequently and information needs are increasing, the network media will obviously become a good choice. In the face of the impact brought by the new media on the Internet, traditional newspapers have set up websites, set up electronic versions of newspapers, and interact with newspapers [6]. Through the development of newspaper network interaction, traditional newspapers have greatly absorbed the technological advantages of the new media on the Internet, and their information content has been updated slowly. The lack of capacity of the content of the information cannot fully meet the disadvantages of the needs of the audience and has been compensated to a certain extent. It also gained the favor of the audience, and thus achieved the economic base advertising income for its own survival and development. However, at the same time, we should also see that due to the lack of relevant practical experience in the early days of newspaper network interaction, and the constraints of external policies, newspaper media and newspaper online media often appear homogeneous in content. Tendency, the information content of traditional newspaper websites is often just a copy of the original content of its paper newspapers, lacking the necessary content innovation. With the continuous development of news network interaction and the maturity of practical experience, the content of news and information on newspaper websites has gradually moved away from a single homogeneous trend, and content innovation continues. Websites created by traditional authoritative party and government newspapers receive separate news and information interviewing rights, and also provide a great impetus for the innovation of their website news and information content, as opposed to the content of paper newspapers. Compared to the innovation of website content in traditional newspapers, commercial websites also make full use of the advantages of their commercial and entertainment players to make new breakthroughs in content. For example, the emergence of "spoofing topics" has brought new ideas and operating perspectives to the production of news topics with its subversion of traditional production methods. The traditional first media newspaper, which has been born for more than 400 years, has never brought revolutionary content changes to it like the internet. The content published and disseminated in traditional newspapers is nothing more than the support of the four major newspapers, such as communication, news, commentary, and news photos, as well as various textual information and symbols carried by these four general rules. However, when the Internet appeared, and these modern communication methods, which embody both the recipient and the passer, are the content of traditional newspapers once they are introduced into newspapers. Become more colorful than before, but also makes the newspaper more "cool." The dissemination practices and attempts of network interaction in these newspapers not only implied the innovative meaning of communication science, but also provided a variety of ideas for newspapers to consider the choice of means and means of dissemination of newspaper content in the information age.

\subsection{Means of Communication with the Media.}

The integration of media carriers is an important aspect of media integration. From the perspective of the practice of electronic newspapers and e-magazines, they embody a new idea: that is, "borrowing" the Internet rather than staying on the Internet. The various media styles that we are accustomed to, such as paper newspapers and television programs presented on televisions, can also exist. However, a fundamental change may occur in the distribution or distribution channels on which they rely, that is, digital networks will replace Existing channels. On the receiving terminal, people can still have a variety of choices. People who prefer the newspaper reading habits can print out the content transmitted on the network. The appearance of electronic newspapers has actually made a certain pave for this; People can use TV to watch the final content. However, it can be expected that there will be more information receiving terminals in the future. They will inherit the advantages of some traditional media, and at the same time have some advantages of electronic devices. 


\section{Development Approaches for the Integration of Traditional Media and New Media}

The integrated marketing strategies of new and old media in the view of media convergence are based on the lack of understanding of new media by domestic companies, the lack of high-quality talent for new media marketing, and the low accuracy of audience capture in new media marketing. In combination with the development trend of media convergence, companies can adopt The means of integration of new media and traditional media marketing continuously integrates the advantages of new media and traditional media, strengthens its ability to seize the information market, establishes an authoritative corporate brand, and effectively uses the means of industrial links to realize the products while effectively grasping the target market. Or the three-dimensional dissemination of services, of course, will also help improve the overall strength of the company.

\subsection{The Fusion of Traditional Media and New Media Technologies.}

Information has exploded, and audiences have been receiving more channels for new information. At the same time, the homogeneous competition among new media has become increasingly fierce, and the information between different media may interfere with each other, thereby weakening the audience's understanding of the company and affecting the brand building effect of the company. Therefore, how to use the advantages of the integration of new media and traditional media to establish a more clear, complete and unified brand image, and to strengthen the application of the brand platform has become the top priority for companies to carry out integrated marketing. In view of the increasing homogeneity of media platforms and the increasing reality of information received by the audience, in the process of corporate integrated marketing, it is necessary to use the advantages of new media and traditional media for brand launch and media brand resource integration. In the process of brand integration marketing, Hospital of Capital Medical University used existing hospital newspapers and new media platforms such as TV, websites, and APP to break the existing situation between the different platforms. The media asset management platform, through the scientific cataloging and digital integration of existing brand-related information, assists in the intelligent indexing and retrieval function, increases the intensity of media content, and effectively expands the application scope of media content while highlighting the hospital's Brand value, improve the recognition of the work of the audience for the hospital. For another example, the Shanghai Media Group uses the promotional advantages provided by the Shanghai TV Channel and the Oriental Broadcasting Station's two traditional media platforms to integrate the media platforms of radio, television, newspapers and websites with the help of the concept of "First Finance". Utilize its own advantages to develop financial data products and public relations services, and use the human resources and information resources of different platforms to achieve brand sharing and dissemination, thus furthering its own marketing and development.

\subsection{Determining the Target Market Traditional Media and New Media Development.}

It promotes the individualization and "fragmentation" of audiences, and it also influences the accuracy of media target market positioning and the distribution of media marketing resources. Under the environment of continuous integration of new media marketing and traditional camps, we can take advantage of the two-way interaction of new media to target market positioning and ensure the accuracy of audience positioning and information dissemination. For example, in the process of dissemination of its own brand, June Fresh used the audience's attention to kitchen consumption information. First, it used the new Beijing newspaper headlines, combined with "smoothing" actions and "a woman's thirty-one flowers. "This type of question, while subverting consumers' stereotype about the kitchen, through the interaction of the conversations leads consumers to think about the kitchen image, the relationship between women and the kitchen, inspires the audience's interest in the brand itself, and makes more use of the audience. The interaction between them clearly defined their consumption needs in the kitchen; followed by the use of the online $\mathrm{H} 5$ marketing interaction model, using the slogan "for the name of the kitchen" to mobilize the audience to participate in the topic discussion and poster production process, achieving an audience-to-brand relationship. Two-way communication enhances the audience's impression of the brand, and also provides the conditions for its own accurate publicity; Finally, with the help of the "June Tasty Kitchen Contest" and "Apron 
Design Contest", the young people in the new media platform have more Advantages, to guide young people to participate in the competition, and then attract different groups of attention to the brand.

\subsection{Create a High-Quality Marketing Team for Traditional Media and New Media.}

From a business perspective, the marketing competition is also the competition of talents. Therefore, in view of the current trend of continuous improvement of the convergence of old and new media, companies need to pay attention to the construction of high-quality marketing teams. Specifically speaking, we can proceed from the following perspectives: First, combine the company's existing products and services to provide knowledge training to marketers, promote their awareness of the renewal of products and information, and continuously supplement their own marketing knowledge; second, use new media technologies. Training to guide marketers to understand and apply new media technologies in order to deliver product information to customers in a timely manner, accept customer inquiries and provide customers with high quality products and services; and finally, cultivate professional new media marketing talents, that is, to cultivate specialized companies. The website marketing talents are mainly used to improve the update capabilities of new media platforms such as corporate websites, feedback capabilities of customer information, and integrated operation capabilities of sexual media.

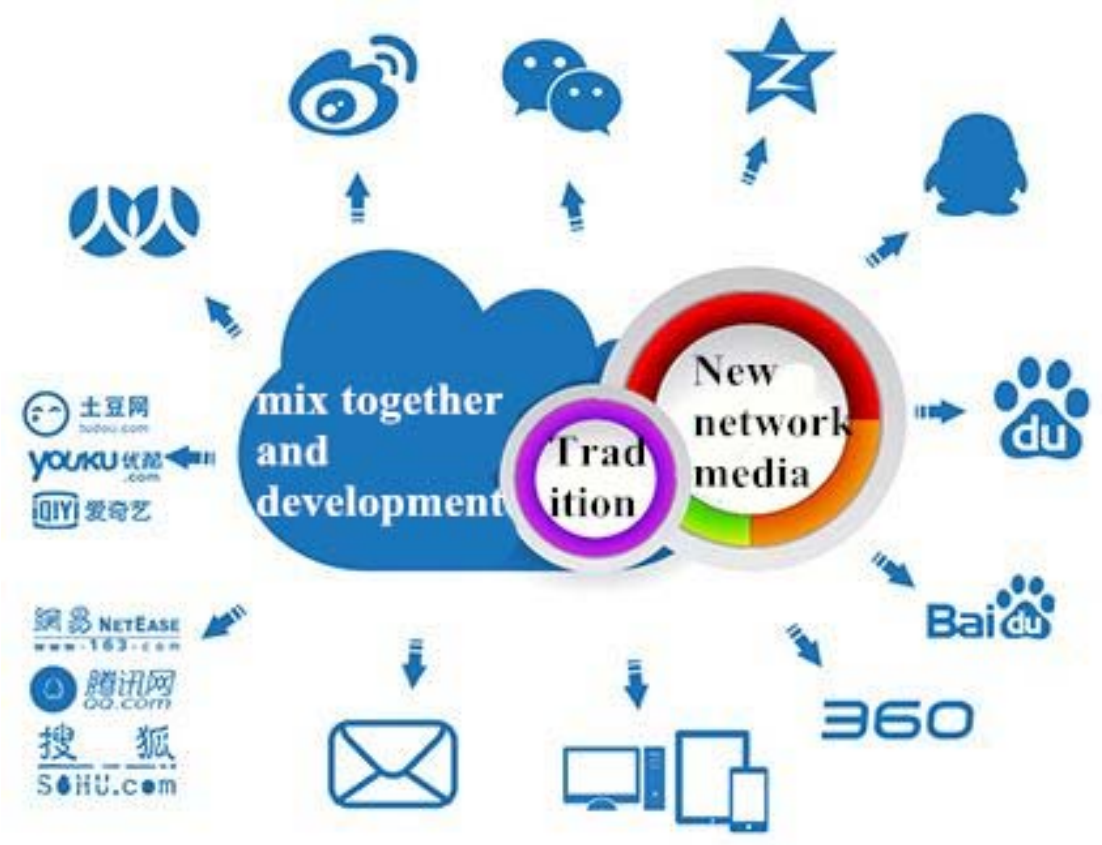

Fig 2. Network new media marketing traditional marketing blended development

\subsection{Achieve Three-Dimensional Coverage of Traditional Media and New Media Audiences.}

In the process of enterprise development, in order to strengthen the comprehensive utilization of new media marketing and traditional media marketing methods, we can build a three-dimensional communication platform model, optimize the existing marketing organization structure, and use multiple marketing models to constantly optimize its own marketing services. First, we can combine the characteristics of existing platforms, grasp the basic characteristics of the new media platform and traditional media business, and design marketing links. Second, use the traditional media's one-way communication characteristics to push information, and use new media to spread the advantages of rich marketing Means to improve service levels, and then promote the formation of mufti-channel interactive mode to meet the information needs of different audience groups. For example, in the marketing process, "People's Daily" included micro blog, We Chat, mobile client and other marketing models into its own marketing system. In the online platform, it also changed the marketing attitude in the traditional media, and used a more pro-civilized language. The open online interactive marketing model relied on ordinary character stories to refocus the media content. At the same time, it also used its own advantages of traditional media to open up multiple communication channels, combining official public opinion information and civil opinion discussions, and transmitting social positive energy. 


\subsection{Establishing Integration of Traditional Media and New Media Industry Links.}

Marketing itself is to take advantage of the development advantages of traditional media and new media, integrate the marketing value of different media, and construct industrial value chains with the most optimized choices to promote the construction of brand image and the improvement of the quality of the company's products or services. In the process of marketing, marketing focuses on the sales of integrated industries such as names and TV commercials. At the same time, it uses the Internet and mobile phones to interact with viewers, guides the audience to participate in the process of program selection, strengthens audience awareness, and promotes the second Season, third season, the formation of the production of the industry, build an industrial value chain, and promote the customer's cyclical investment and product promotion.

\section{Conclusion}

The development of new media is still at an exploratory stage, so most companies' marketing activities will present a situation where new media marketing and traditional marketing coexist. In this situation, companies need to grasp the marketing advantages of traditional media and effectively use the authority of traditional media; at the same time, they must grasp the basic characteristics of new media marketing, use new media, such as social marketing, event marketing, and integrate existing marketing. Concept, forming a three-dimensional marketing industry chain, and promote the company to continuously adapt to the new media development environment, and then promote the development of integrated enterprise development capabilities and market competitiveness. Of course, it also provides conditions for the improvement of the application level of new media in China, the enrichment of new media research theories, and the summary of practical experience, and promotes the development of our country's overall new media development capability and the improvement of economic development level.

\section{Acknowledgments}

The paper is supported by National Natural Science Foundation of China for Youth "Mechanism of luxury brand corporate social responsibility activities backfire effect on consumer behavior" (71502133), Social Science Foundation of Shaanxi Province "Research on the influence of corporate charity to consumer perception” (2015R018).

\section{References}

[1]. Jiang Yeanling, et al. The Age of Media Culture and Consumption", Central Compilation and Translation Press, Vol. 5(2012) No.36, p.123-129.

[2]. Tao Dan Zhang Haora, et al. New Media and Online Advertising", Science Press, Year Month

[3]. Zhou Qian, et al. The Profit Model of Online Media", Global Brand Network Date, Vol. 12 (2014) No.16, p.346-351.

[4]. Long Hoping, ET al. Discussion on the Problems and Countermeasures of New Media Marketing of Chinese Enterprises. Science and Technology Entrepreneurs, Vol.9 (2013) No.20, p.298-302.

[5]. Wang Change, Zhang Fan, et al. Research on the Strategy of Traditional Media Marketing Based on Social Network Websites. Non-Governmental Science \& Technology, Vol. 10 (2012) No. 24, p.171-178.

[6]. Zhao Xuedong, et al. Analysis of New Media Marketing Strategy in the Information Age. New Media Studies, Vol. 6 (2015) No. 33, p261-266. 